\title{
Study on Power Switching Process of a Hybrid Electric Vehicle with In-Wheel Motors
}

\author{
Shaohua Wang, ${ }^{1}$ Chunrong He, ${ }^{1}$ Hao Ren, ${ }^{2}$ Long Chen, ${ }^{1}$ and Dehua Shi ${ }^{1}$ \\ ${ }^{1}$ School of Automobile and Traffic Engineering, Jiangsu University, Zhenjiang 212013, China \\ ${ }^{2}$ Key Laboratory of Ministry of Public Security for Road Traffic Safety, Wuxi 214151, China \\ Correspondence should be addressed to Shaohua Wang; 15695110293@163.com
}

Received 11 March 2016; Revised 20 June 2016; Accepted 10 July 2016

Academic Editor: Guangming Xie

Copyright (c) 2016 Shaohua Wang et al. This is an open access article distributed under the Creative Commons Attribution License, which permits unrestricted use, distribution, and reproduction in any medium, provided the original work is properly cited.

\begin{abstract}
Hybrid electric vehicles with in-wheel motors (IWM) achieve a variety of driving modes by two power sources-the engine and the IWM. One of the critical problems that exists in such vehicle is the different transient characteristics between the engine and the IWM. Therefore, switching processes between the power sources have noteworthy impacts on vehicle dynamics and driving performance. For the particular switching process of the pure electric mode to the engine driving mode, a specific control strategy coordinating clutch torque, motor torque, and engine torque was proposed to solve drivability issues caused by inconsistent responses of different power sources during the mode transition. The specific switching process could be described as follows: the engine was started by IWM with the clutch serving as a key enabling actuator, dynamic torque compensation through IWM was implemented after engine started, and, meanwhile, engine speed was controlled to track the target speed through the closed loop PID control strategy. The bench tests results showed that the vehicle jerk caused during mode switching was reduced and fast and smooth mode switching was realized, which leads to the improvement of vehicle's riding comfort.
\end{abstract}

\section{Introduction}

Hybrid electric vehicle with IWM has advantages as independent controllable power sources, superior dynamic performance, and so forth. It can make full use of each driving wheel adhesion performance and further improve vehicle's power and driving safety [1]. However, the torque coordinated control strategy of the hybrid electric vehicle with IWM is also the key technical problem nowadays; the different torque and speed responses of the engine and the IWM during different driving mode switching processes will lead to vehicle's unstable power output and poor driving performance. Therefore, on the basis of the energy saving and emission reduction of the vehicle, the power switching process must be effectively controlled so as to improve the driving performance [2].

Based on the above problems, the domestic and foreign scholars have carried out systematic studies, but mainly using the rapid response characteristics of the motor to complete the torque compensation during power switching. The Toyota Corporation's THS uses a power coupling device with a planetary gear, which can obtain the engine output torque by means of the motor output torque in proportion; the compensation torque of the motor is determined by the difference before and after power switching, so THS can eliminate the torque ripple during this process $[3,4]$. Davis and Lorenz took ISG hybrid electric vehicle as research object; they established an engine torque observer for realtime calculation of the engine torque ripple. This ripple could be counteracted effectively by motor compensation torque [5]. For CVT hybrid electric vehicle, Zhang et al. calculated the motor speed by using the pseudo target speed and the pseudo output torque of the engine and achieved a smooth transition from the pure electric mode to the pure engine operating mode [6]. Koprubasi converted the hybrid electric vehicle power switching problem into hybrid systems switching control issue, and the experimental results showed that the switching control strategy based on hybrid systems could reduce the impact of the power switching process effectively [7]. Tong presented a dynamic coordination control strategy, its basic algorithm could be expressed as engine torque openloop control with dynamic engine torque estimation and 


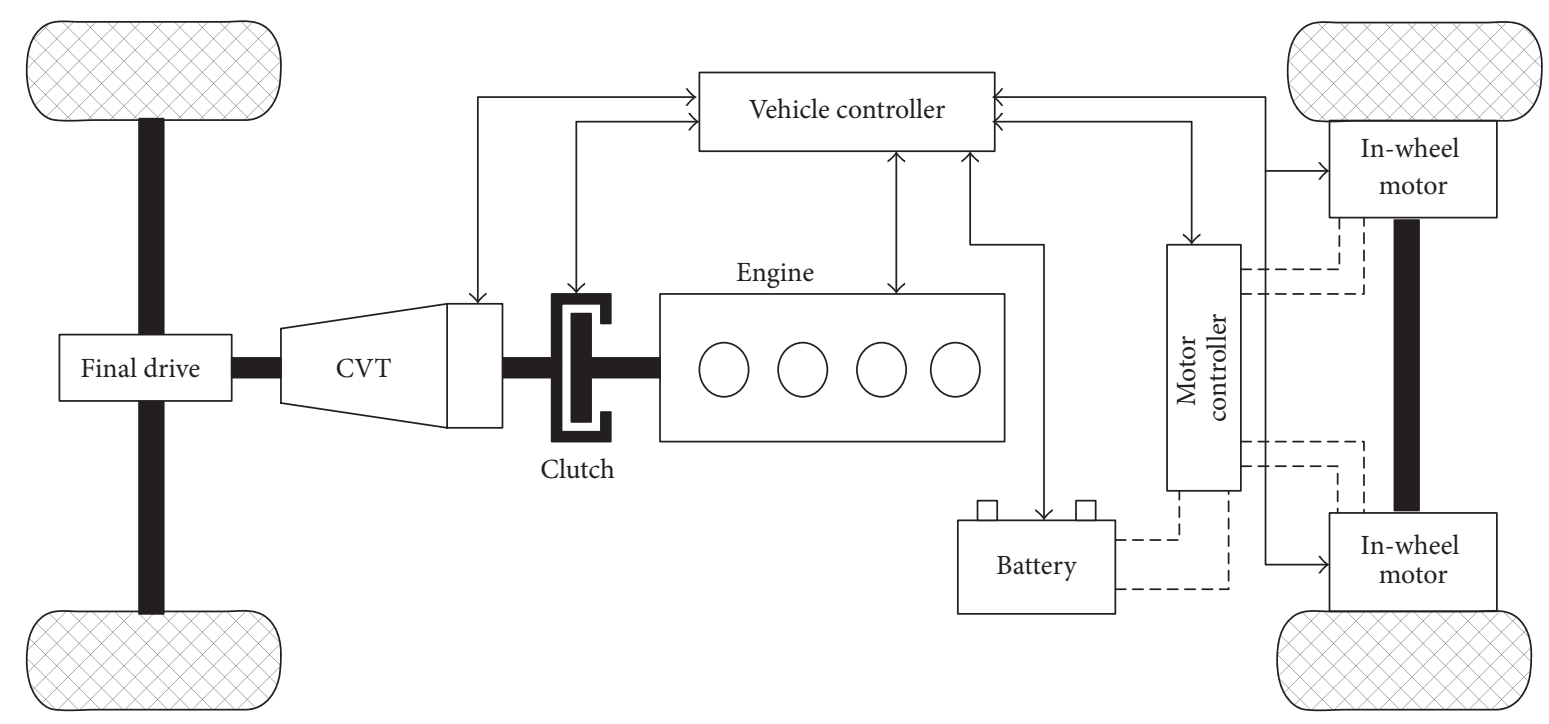

FIGURE 1: Structure of the hybrid power drive system.

torque compensation by motor, and the effect of the control strategy was verified by experiments [8]. However, the above researches mainly take the engine and motor as the controlled devices, and torque compensation control of the engine is carried out by the motor, which put a high requirement for the motor dynamic performance. At the same time, the engine is still activated by ISG in most of the researches, but researches on the structures in which driving motors are used to start the engine are insufficient as well as the control strategies for such specific starting process. Besides, researches on hybrid electric vehicle mode switching quality caused by clutch engagement are rarely studied as well.

In this paper, a hybrid electric vehicle with IWM was selected as target research object, engine was started by the IWM directly, and the structure and dynamic relationship of the drive system were analyzed; according to the engine MAP diagram, working modes of the hybrid electric vehicle were determined; the switching process of the pure electric mode to the engine drive mode was selected as a key research target; a power switching control strategy of starting the engine by motor constant torque compensation and dynamic torque compensation by the motor after engine's start-up was developed; a fast prototype control test scheme was designed and carried out, which was used to conduct an experimental study on the specific process of the pure electric driving mode to the engine driving mode.

\section{Hybrid System with IWM}

2.1. Drive System Structure. The structure of the hybrid power drive system with IWM researched in this paper is shown in Figure 1, which is developed from the traditional frontengine, front-wheel-drive (FF) layout vehicle type, the original drive system structure is retained, engine is concentrically arranged along with the clutch and CVT gearbox, and power is output from front axle. On this basis, the IWM are fixed on the rear wheels to drive the rear axle directly. The main
TABLE 1: Vehicle components selection and parameters.

\begin{tabular}{lccc}
\hline \multirow{2}{*}{ Component } & \multirow{2}{*}{ Component selection } & \multicolumn{2}{c}{ Main technical parameters } \\
& \multirow{2}{*}{ Parameter } & Value \\
\hline \multirow{2}{*}{ L4 DVVT } & $\begin{array}{c}\text { Power } \\
\text { Peak torque }\end{array}$ & $\begin{array}{c}93 \mathrm{~kW} \\
160 \mathrm{Nm}\end{array}$ \\
\hline \multirow{2}{*}{ IWM } & \multirow{2}{*}{ PMSM } & $\begin{array}{c}\text { Power } \\
\text { Peak torque }\end{array}$ & $\begin{array}{c}8 \mathrm{~kW} \\
300 \mathrm{Nm}\end{array}$ \\
\hline \multirow{2}{*}{ Transmission } & \multirow{2}{*}{ Steel-belt CVT } & $\begin{array}{c}\text { Ratio } \\
\text { coverage }\end{array}$ & $0.39 \sim 2.44$ \\
\cline { 3 - 4 } Battery pack & \multirow{2}{*}{ Lithium battery } & $\begin{array}{c}\text { Rated voltage } \\
\text { Capacity }\end{array}$ & $336 \mathrm{~V}$ \\
& & $22 \mathrm{Ah}$ \\
\hline
\end{tabular}

components selection and parameters setting of the hybrid electric vehicle are shown in Table 1.

2.2. Working Modes Analysis. According to the vehicle dynamics theory, the dynamic relationship of the hybrid electric vehicle with in-wheel motors can be obtained [9]:

$$
\begin{gathered}
T_{r}=T_{e} i_{g} i_{0} \eta_{T}+T_{m} \eta_{m}, \\
\omega_{r}=\omega_{m}=\frac{\omega_{e}}{i_{g} i_{0}},
\end{gathered}
$$

where $T_{r}$ is, at current speed, the demand torque of the wheel; $T_{e}$ is engine torque; $T_{m}$ is torque of IWM; $i_{g}$ is transmission ratio; $i_{0}$ is final driver ratio; $\eta_{T}$ is transmission efficiency; $\eta_{m}$ is efficiency; $\omega_{r}$ is wheel speed; $\omega_{m}$ is IWM speed; and $\omega_{e}$ is engine speed.

The engine and IWM are settled on the front and rear axle, respectively; vehicle demand torque can be provided by engine and IWM, respectively, or together. The IWM has higher efficiency, because it is connected with the wheel directly. The fuel consumption of the vehicle is the most intuitionistic evaluation index; there are obvious differences 
TABLE 2: Vehicle working modes.

\begin{tabular}{lcccc}
\hline Working mode & Engine & $\begin{array}{c}\text { Component working states } \\
\text { IWM }\end{array}$ & Clutch & Speed \& torque \\
\hline Pure electric & Off & Traction motor & Separated & $T_{r}=T_{m} \eta_{m}, T_{e}=0 ; \omega_{r}=\omega_{m}, \omega_{e}=0$ \\
Engine driving alone & On & Off & Engaged & $T_{r}=T_{e} i_{g} i_{0} \eta_{T}, T_{m}=0 ; \omega_{r}=\omega_{m}=\frac{\omega_{e}}{i_{g} i_{0}}$ \\
Compound drive & On & Traction motor & Engaged & $T_{r}=T_{e} i_{g} i_{0} \eta_{T}+T_{m} \eta_{m} ; \omega_{r}=\omega_{m}=\frac{\omega_{e}}{i_{g} i_{0}}$ \\
Driving and generating & On & Generator & Engaged & $T_{r}=T_{e} i_{g} i_{0} \eta_{T}-T_{m} \eta_{m g} ; \omega_{r}=\omega_{m}=\frac{\omega_{e}}{i_{g} i_{0}}$ \\
Regenerative braking & Off & Generator & Separated & $T_{r}=-T_{m} \eta_{m g}, T_{e}=0 ; \omega_{r}=\omega_{m}, \omega_{e}=0$ \\
\hline
\end{tabular}

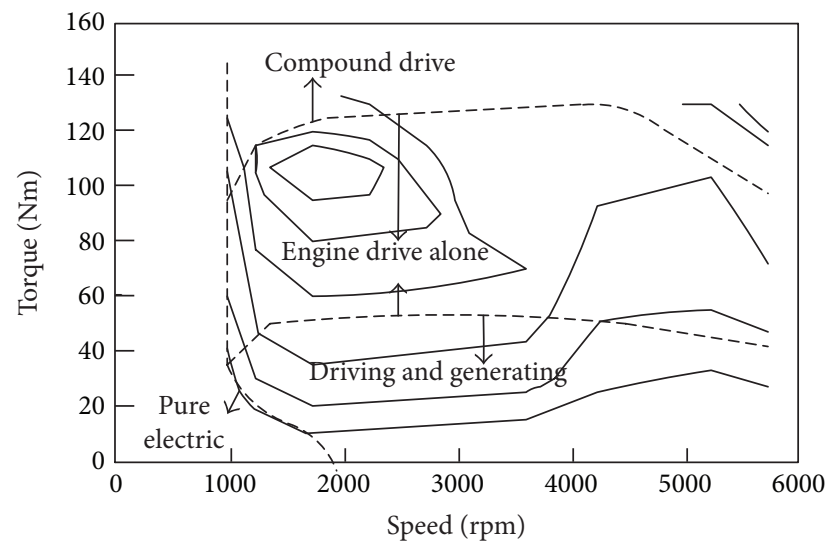

FIGURE 2: Mode partition diagram.

under different conditions of the engine [10]. So, the power switching issues of the vehicle driving cycle are mainly tackled in this paper. Taking engine fuel economy as the evaluation criterion, the vehicle operating ranges are divided reasonably based on the engine fuel consumption MAP diagram, which is in premise of the vehicle driving torque required and giving full consideration to the engine's fuel economy, as shown in Figure 2.

In Figure 2, the modes are divided based on the engine optimal minimum torque curve, the engine maximum torque curve, and the engine lowest speed curve. Vehicle is driven by the IWM only, when the engine speed is low; when the engine works in the range of high speed and low torque, vehicle is supposed to work in the driving and power generating state; while engine works in the high torque range with better fuel economy, it also provides IWM with redundant torque for power generation; vehicle is driven by the engine alone, when engine speed is at a high level and its operating point located in the optimized torque range; when engine torque is high enough, vehicle is in a compound driving state, in which engine only provides the optimized maximum torque, and the remaining torque is provided by the IWM. The working modes of the hybrid electric vehicle are shown in Table 2, where $\eta_{\mathrm{mg}}$ is the power generation efficiency.

From Table 2, the engine is closed only in pure electric mode but working in other three modes. Because vehicle is not equipped with ISG, extra motor assistant torque is needed in the engine starting process; meanwhile, the fluctuation of engine speed and torque will directly affect the stability and comfort of the power transmission. Therefore, the processes of pure electric mode to the other three driving modes are particularly vital. In this paper, the process of the pure electric mode to the engine driving mode is chosen as the typical process, and a series of control studies have been carried out based on this process.

\section{Power Switching Control Strategy}

In the specific process of pure electric mode to engine driving mode, the IWM not only provide the vehicle driving torque but also provide the extra torque to make the engine reach its idle speed as soon as possible. After starting, engine speed should be stabilized down in a shorter run. Considering the actual speed fluctuation during engine's start-up, the engine speed must be controlled because it cannot meet the actual speed requirements during the mode switching, speed controlling can make the engine track the CVT speed in a very short time, and vehicle is driven by engine alone after clutch fully engaged. Due to the delay of the engine, its actual output torque cannot meet the actual demand torque after clutch engaged, so compensation torque provided by IWM is needed to improve the vehicle driving comfort. Therefore, the mode switching process is subdivided into three stages, as shown in Figure 3.

\subsection{Coordination Control of the Engine Starting Process}

3.1.1. Clutch Engagement Pressure Control. The hybrid electric vehicle with IWM researched in this paper does not contain ISG; engine reaches its predetermined ignition speed and starts up through the torque provided by IWM.

The engine starting torque and constraints are as follows:

$$
\begin{gathered}
T_{\mathrm{es}}-T_{r}=J \dot{\omega}, \\
t \leq 0.4, \\
\frac{60}{2 \pi} \int_{0}^{t} \dot{\omega} d t \geq 800,
\end{gathered}
$$

where $T_{\mathrm{es}}$ is the engine starting torque, $T_{r}$ is the drag torque on the crankshaft, $J$ is the flywheel inertia, $t$ is the period 


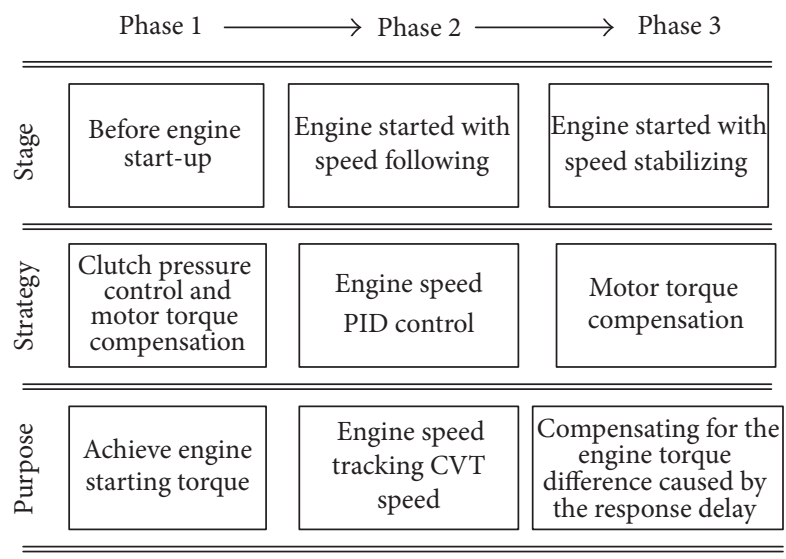

FIGURE 3: Control process of mode switching.

of time in which the flywheel reaches its predetermined rotational speed, and $\omega$ is the crankshaft speed.

The IWM torque is transmitted to the engine output shaft through front-wheel, main reducer, CVT, and clutch. The starting torque delivered to the engine is determined by the clutch engagement pressure [11]. The engagement and disengagement processes of the wet clutch selected in this paper are smooth and controllable; torque transmitted by the clutch is controlled by active control of the clutch's engagement pressure between driving disc and driven disc. The transferred clutch torque can be expressed as

$$
T_{c}=z \cdot \mu_{c} \cdot A_{c} \cdot P_{c} \cdot \operatorname{sgn}\left(\Delta_{c}\right),
$$

where $T_{c}$ is the clutch torque; $z$ is the number of clutch friction plates; $\mu_{c}$ is friction coefficient of the friction plate (the thermal effect of $\mu_{c}$ is ignored); $A_{c}$ is the effective area of the friction plate; $P_{c}$ is the clutch pressure; $\Delta_{c}$ is the differential rotation speed between driving disc and driven disc; and sgn is the symbol function; when $\Delta_{c}$ value is positive, function returns 1 , when $\Delta_{c}$ value is 0 , function returns 0 , and when $\Delta_{c}$ value is negative, function returns -1 .

According to (2) and (3), the clutch engagement pressure during engine starting process is

$$
P_{c}=\frac{T_{\mathrm{es}}}{z \cdot \mu_{c} \cdot A_{c} \cdot \operatorname{sgn}\left(\Delta_{c}\right)} .
$$

3.1.2. IWM Compensation Torque. On the basis of determined engine starting torque and clutch engagement pressure, the additional compensation torque provided by the IWM is

$$
\begin{gathered}
T_{m}=T_{m r}+T_{m s}, \\
T_{m s}=T_{\mathrm{es}} i_{0} i_{\mathrm{cvt}},
\end{gathered}
$$

where $T_{m}$ is the output torque of the IWM; $T_{m r}$ is the vehicle driving torque; and $T_{m s}$ is the additional compensation torque provided by the IWM.

3.1.3. Engine Speed Control. Proportional-Integral-Derivative (PID) control can achieve satisfying results by adjusting

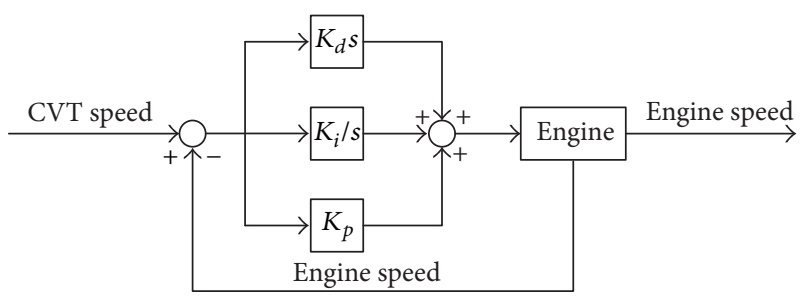

FIGURE 4: Engine speed PID control structure.

parameters in experience; it has simple structure and is widely used in engineering tests [12]. In this paper, PID control is used to stabilize the engine speed, as shown in Figure 4.

The engine speed PID controller's inputs are the CVT speed and the actual engine speed error; output is the engine speed. $K_{p}, K_{i}$, and $K_{d}$ in this diagram are the proportional, integral, and differential parameters, respectively. Through the analysis of the response characteristics of the engine speed, the parameters above are adjusted to achieve optimal control effects [13].

3.1.4. Torque Compensation Control after Engine Started. Vehicle is driven by the engine alone, when the clutch is engaged, but the engine's actual output torque can not reach the demand torque immediately, and this specific process can be described as

$$
T_{\mathrm{er}}=T_{\mathrm{eo}}+\Delta T_{e},
$$

where $T_{\text {er }}$ is the engine demand torque, $T_{\text {eo }}$ is the engine actual output torque, and $\Delta T_{e}$ is the torque difference. Extra IWM torque is still needed in this period of time; the value is

$$
T_{m}=\Delta T_{e} i_{0} i_{\mathrm{cvt}} .
$$

When the actual torque of the engine is fully in accord with the requirement, the IWM stop providing compensation torque, which complete the mode switching control.

\section{Bench Test}

Based on the designed power switching control strategy, a rapid control prototype (RCP) of the hybrid electric vehicle mode switching process is constructed by using the dSPACEMicroAutoBox. The control model is converted into $\mathrm{C}$ code and downloaded to the high performance processor of the real-time hardware system. With the help of real-time hardware system interface, the vehicle control unit prototype is established and regarded as a main part of the bench along with the engine, IWM, and other parts. The rapid control prototype diagram is shown in Figure 5, and the layout of test bench is shown in Figure 6.

The test bench consists of a load dynamometer, a fourcylinder inline engine, and the IWM. Engine, clutch, and CVT are coaxially arranged as parts of the front axle; engine and CVT are connected through the clutch, the clutch is hydraulically actuated. Double motor structure of the original model is replaced by single IWM as simplified rear axle, and 


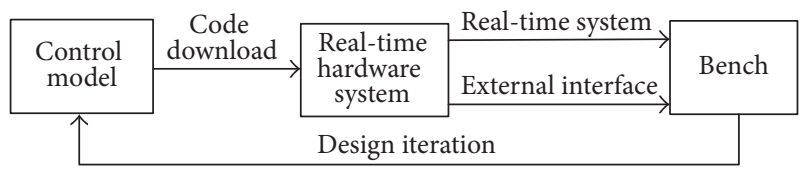

FIGURE 5: Rapid control prototype.

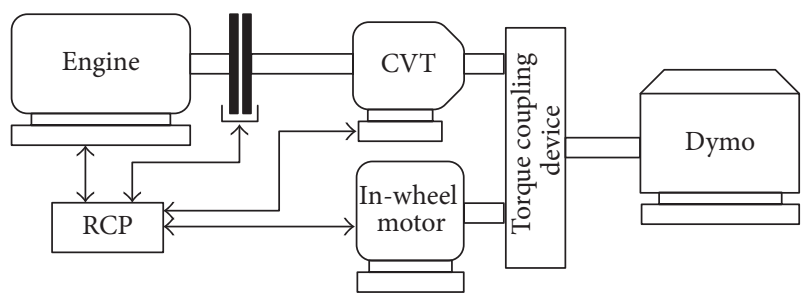

FIgURE 6: Test bench layout.

IWM outputs torque through direct torque control; power of the front and rear axles is coupled and output to load dynamometer through the torque coupling device, which makes the bench tests of the hybrid electric vehicle with IWM possible to be realized. The torque coupling device adopts the belt coupled structure, which can achieve linear superposition of torque; load dynamometer can simulate the vehicle load and monitor vehicle output power in real-time; RCP is conducted by using dSPACE-MicroAutoBox. As the control unit, MicroAutobox can realize the signal connection with the engine, IWM, CVT, and the multidisk wet clutch through can-bus, and it also can realize the active control of the above components and achieve expected effects of the power switching control in this paper. Part of the test bench is shown in Figure 7.

4.1. Test Condition. Typical operating condition of the transition from the pure electric mode to the pure engine operating mode is selected as the specific experimental condition; based on this, a series of mode switching control tests are carried out. In order to realize the proper operation modes switching in the tests, vehicle is given a constant demand torque, so it can be driven by the IWM firstly and then turn into the engine driving mode at a specific time, and this is considered as the working condition to be researched in this paper. Comparative tests using dynamic torque compensation strategy (with control strategy) or conventional torque distribution strategy (without control strategy) of the mode switching process are conducted.

4.2. Test Results. Compared with the test which has control strategy involved, when there is no control strategy, the IWM output torque is in well accordance with the original set value before the engine starts up and outputs torque in the switching process of the pure electric mode to the engine driving mode; the IWM are shut down, when engine finishes its start-up, after that, vehicle is driven by the engine only, and mode switching is completed. The mode switching process with control strategy involved can be divided into three phases which are before, during, and after switching.

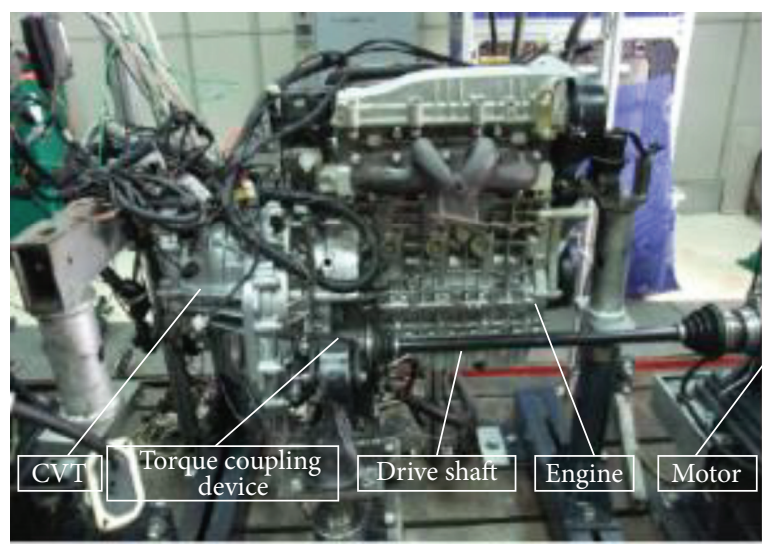

Figure 7: Test bench.

Figure 8 is the clutch engaging pressure diagram during power switching. Depending on whether there is control strategy, Figures 8(a) and 8(b) are the results, respectively. Clutch engaging pressure rises rapidly in Figure 8(a) at the beginning of power switching process but becomes stable at a higher level eventually, which indicates that the clutch is switching from the separate state to the fully engaged state in this process. In Figure 8(b), the clutch is in a state of separation before switching, the engaging pressure is 0 , then the pressure increases and maintains a medium level, and the pressure further increases and remains stable after switching, such that the active control of clutch engaging pressure is realized.

Diagrams of engine speed tracking are shown in Figure 9; Figure 9(a) is without control strategy, while Figure 9(b) is with control strategy. In Figure 9(a), engine reaches its starting speed as the clutch is engaging, there are some fluctuations after the engine start-up, which last for a period of time then tend to be stable, and the engine speed is completely following the output speed of the CVT during this process. Compared with no control strategy, in Figure 9(b), engine is off before mode switching, its speed is 0 , then the speed increases to the idle speed, and engine is started; through the PID speed control, engine speed catches the CVT input speed rapidly, and there is no speed fluctuation in this process; after switching, engine speed is consistent with the speed of the CVT input terminal.

The output torque of the IWM is shown in Figure 10. In Figure 10(a), the IWM real-time output torque is in accordance with the vehicle demand torque in the pure electric mode. In the process of the mode switching, while engine has not completed its start-up and output no torque, the IWM still provide torque according to the vehicle demand, and part of the torque is used to start the engine during this process, so the vehicle driving torque is lower than the demand torque; after engine start-up and outputting torque, the IWM are off and the mode switching is completed. Compared with no control strategy, as shown in Figure 10(b), the output torque of the IWM is in complete agreement with the vehicle demand before the mode switching, when there is control strategy involved. The IWM provide extra torque to start the 


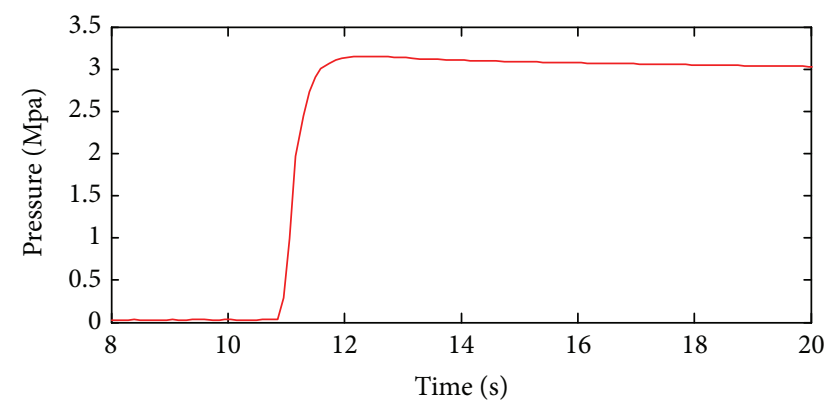

(a) Without control strategy

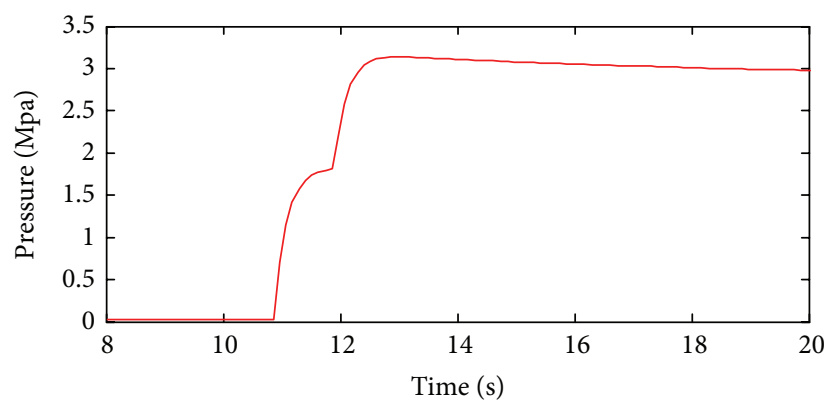

(b) With control strategy

FIGURE 8: Clutch engaging pressure.

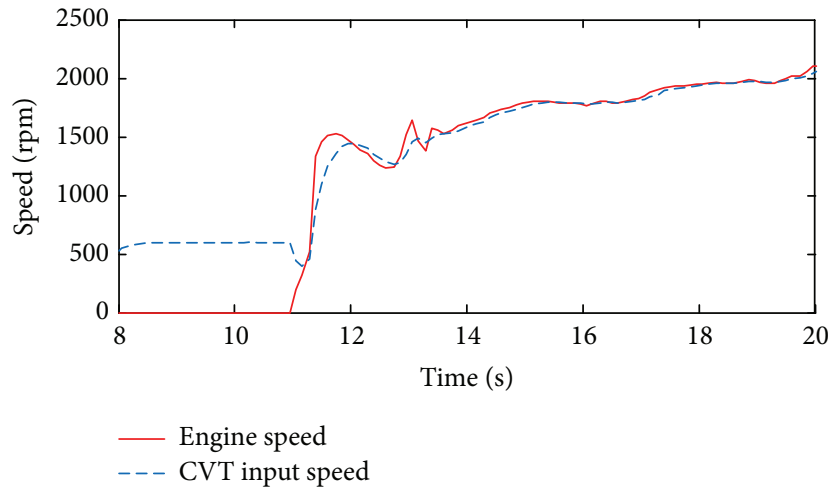

(a) Without control strategy

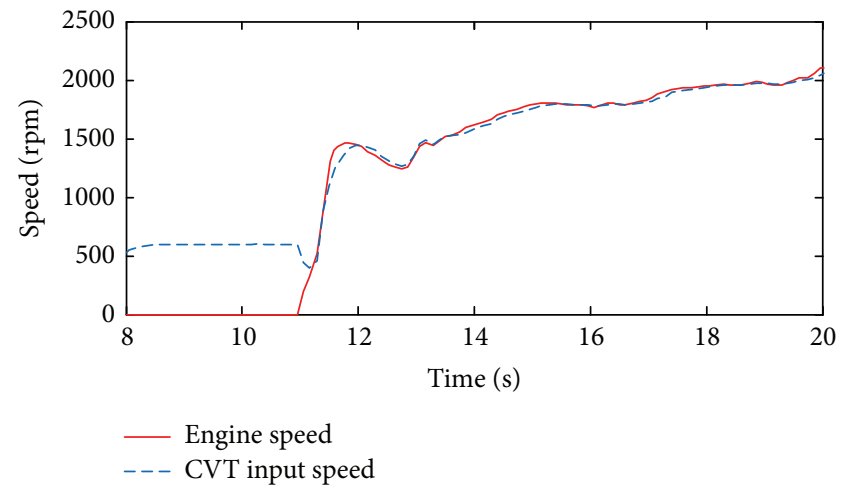

(b) With control strategy

FIGURE 9: Engine speed tracking.

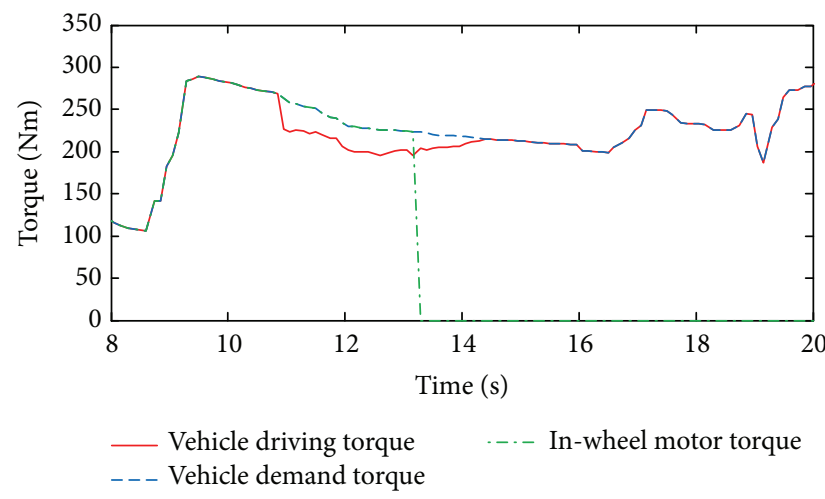

(a) Without control strategy

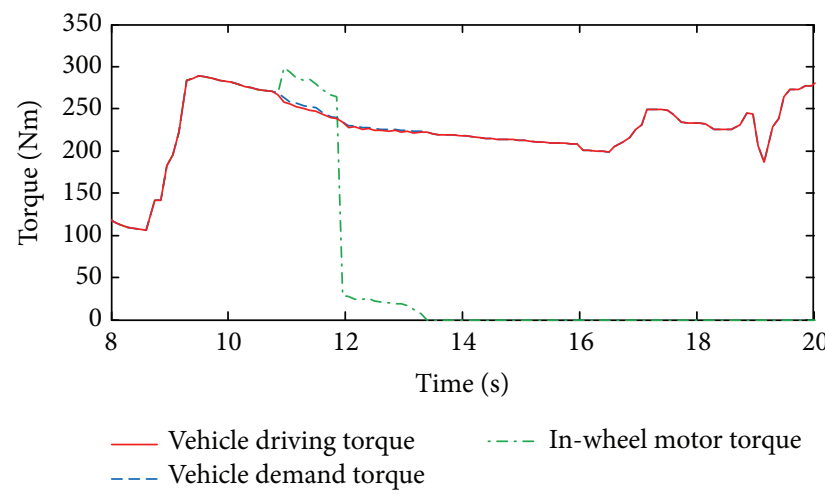

(b) With control strategy

FIgURe 10: IWM torque.

engine while maintaining the vehicle demand torque during the mode switching, after the switching, the IWM continue to provide the compensation torque to supply the insufficient torque caused by the engine's response lag, and this process lasts until the engine can meet the vehicle demand torque in real-time. In the whole process, the vehicle driving torque is consistent with the vehicle's demand torque, and no obvious torque shortage is observed.

Figure 11 is the engine torque diagram with and without control strategy, as can be seen, compared with no control strategy, the engine torque has a faster lifting speed and a higher starting value, so the engine's start-up is completed in a shorter time.

The diagram of the vehicle jerk considering whether there is control strategy or not is shown in Figure 12. In this Figure, the sharp jerks of the vehicle are generated both in positive and in negative directions during mode switching, when there is no control strategy, the maximum value of the jerk reaches $39.1 \mathrm{~m} \cdot \mathrm{s}^{-3}$, which will have great influence on vehicle's performance. Vehicle jerk has been well controlled while 


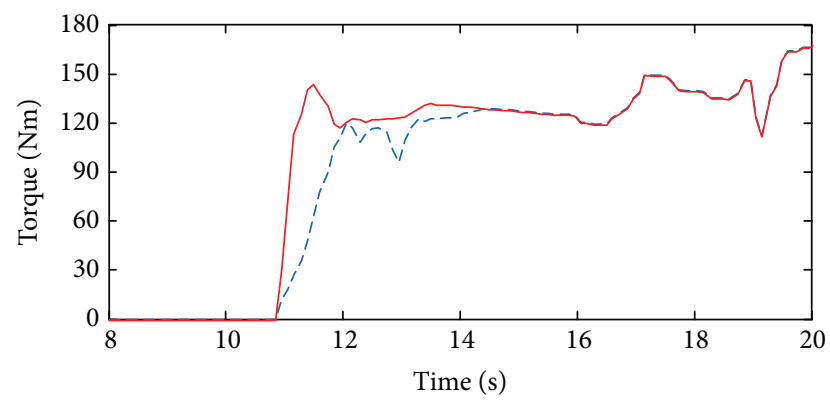

Without control - - - With control

FIGURE 11: Engine torque.

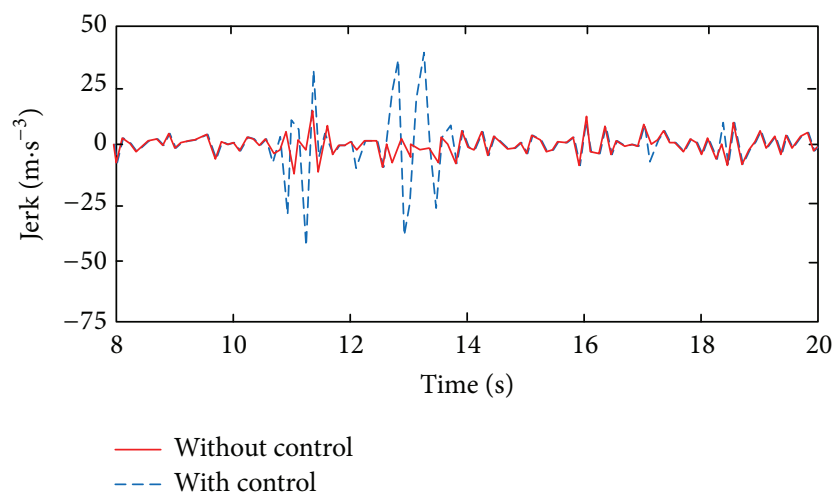

Figure 12: Vehicle jerk.

there is control strategy involved, the jerk value is reduced, the maximum is also reduced by $64 \%$, up to $14.06 \mathrm{~m} \cdot \mathrm{s}^{-3}$, and, compared with the former situation, it is even lower than the recommended value of $17.64 \mathrm{~m} \cdot \mathrm{s}^{-3}$. At the same time, the range of the jerk is also reduced, which is mainly narrowed in the short period between preswitching and intraswitching.

\section{Conclusions}

For the hybrid electric vehicle with IWM, a power switching control strategy is developed for the specific process of the pure electric mode to the engine driving mode, a target test bench is built, and the validity of the control strategy is verified:

(1) Through the bench test, the power switching control strategy is verified to ensure that the pure electrical mode can be switched to the engine driving mode, the driving torque is maintained normally during the switching, and the vehicle shock is effectively limited.

(2) The clutch engaging pressure is controlled in the process of mode switching, and the engine starting torque is reasonably determined. At the same time, under the control of PID, the engine speed has no significant fluctuation, and it can track the input speed of the CVT quickly.
(3) Clutch is fully locked in the mode switching process; therefore the clutch works under fixed pressure, which is suitable for engines with specific parameters. Formulating new control strategies for different types of engines and different switching requirements will be the next research focuses.

\section{Competing Interests}

The authors declare that there is no conflict of interests regarding the publication of this paper.

\section{References}

[1] E. Mehrdad, G. Yimin, E. G. Sebastien et al., Modern Electric, Hybrid Electric and Fuel Cell Vehicles: Fundamentals, Theory, and Design, CRC Press, Boca Raton, Fla, USA, 2008.

[2] C. Espanet, M. Tekin, R. Bernard, A. Miraoui, and J.-M. Kauffmann, "A new structure of an high torque in-wheel motor," in Proceedings of the 6th IEEE International Conference on Electrical Machines and Systems (ICEMS '03), vol. 1, pp. 158-162, Beijing, China, November 2003.

[3] A. Kimura, T. Abe, and S. Sasaki, "Drive force control of a parallel-series hybrid system," JSAE review, vol. 20, no. 3, pp. 337-341, 1999.

[4] K. Moriya, Y. Ito, Y. Inaguma et al., "Design of the surge control method for the electric vehicle powertrain," SAE Technical Paper 2002-01-1935, 2002.

[5] R. I. Davis and R. D. Lorenz, "Engine torque ripple cancellation with an integrated starter alternator in a hybrid electric vehicle: implementation and control," IEEE Transactions on Industry Applications, vol. 39, no. 6, pp. 1765-1774, 2003.

[6] J. Zhang, Y. Zhou, W. Huang, and C. Cao, "A study on mode switching smoothly on hybrid electric vehicle based on CVT," in Proceedings of the International Conference on Remote Sensing, Environment and Transportation Engineering (RSETE '11), pp. 972-975, IEEE, Nanjing, China, June 2011.

[7] K. Koprubasi, Modeling and control of a hybrid-electric vehicle for drivability and fuel economy improvements [Ph.D. Dissertation], The Ohio State University, Columbus, Ohio, USA, 2008.

[8] Y. Tong, Study on the coordinated control issue in parallel hybrid electric system [Ph.D. thesis], Library of Tsinghua University, Beijing, China, 2004.

[9] R. Rajamani, Vehicle Dynamics and Control, Mechanical Engineering Series, Springer, New York, NY, USA, 2nd edition, 2012.

[10] A. Sciarretta and L. Guzzella, "Control of hybrid electric vehicles," IEEE Control Systems Magazine, vol. 27, no. 2, pp. 6070, 2007.

[11] A. Smith, N. Bucknor, H. Yang et al., "Controls development for clutch-assisted engine starts in a parallel hybrid electric vehicle," SAE Technical Paper 2011-01-0870, 2011.

[12] I. Haider, H.-U.-R. Khalid, and U. S. Khan, "An initial study of PID and Fuzzy PID controller design for non-linear SI engine speed and AFR control," in Proceedings of the 14th International Conference on Control, Automation and Systems (ICCAS '14), pp. 437-442, IEEE, Seoul, South Korea, October 2014.

[13] K. Suzuki, Control System Basics and PID Control, Springer, Tokyo, Japan, 2013. 


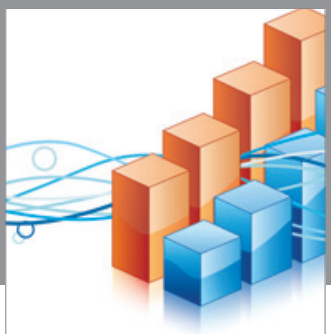

Advances in

Operations Research

vatem alat4

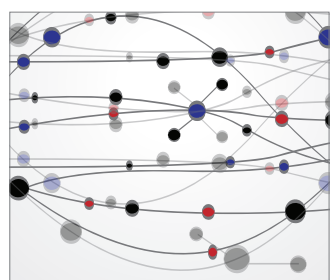

\section{The Scientific} World Journal
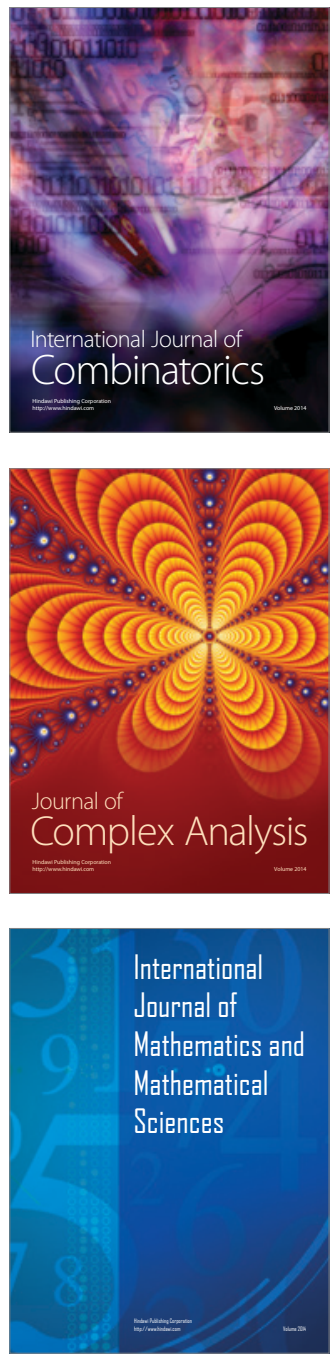
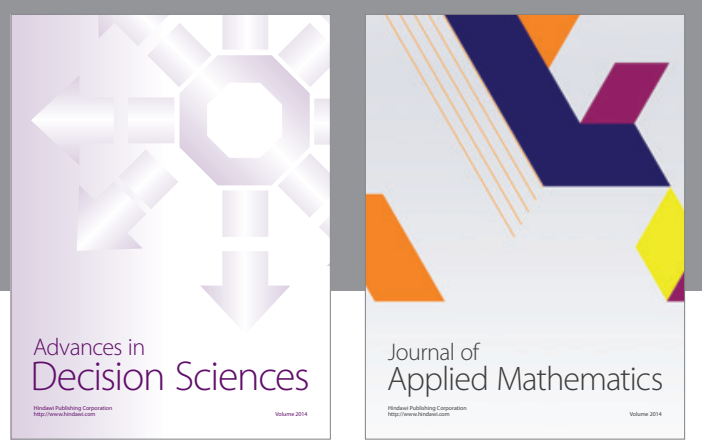

Algebra

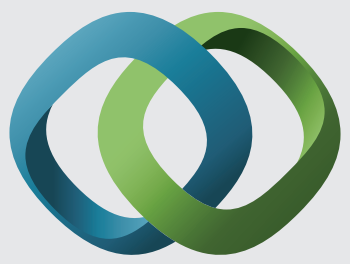

\section{Hindawi}

Submit your manuscripts at

http://www.hindawi.com
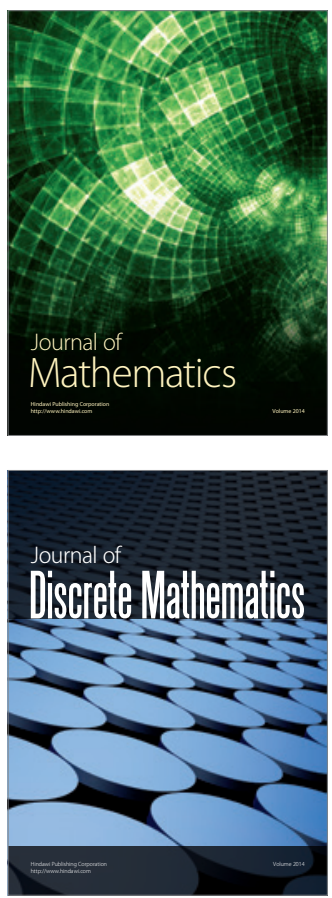

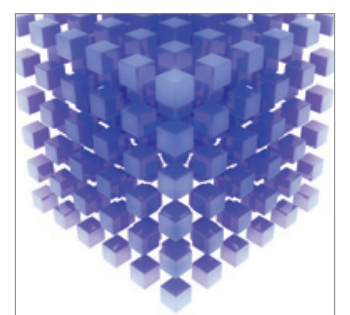

Mathematical Problems in Engineering
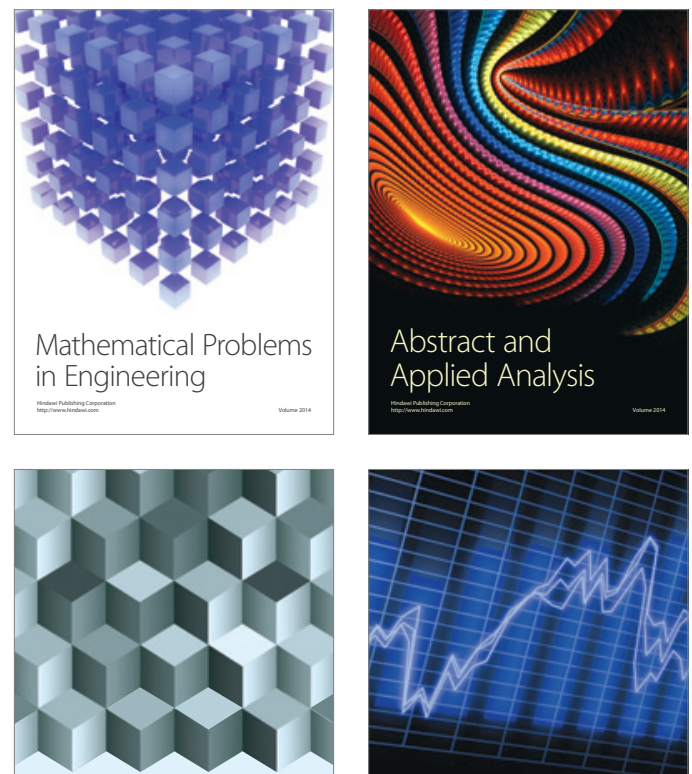

Journal of

Function Spaces

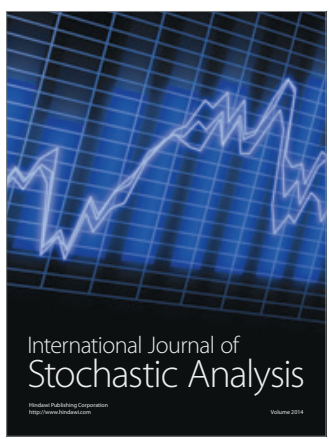

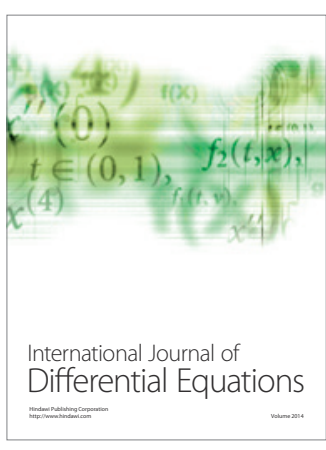
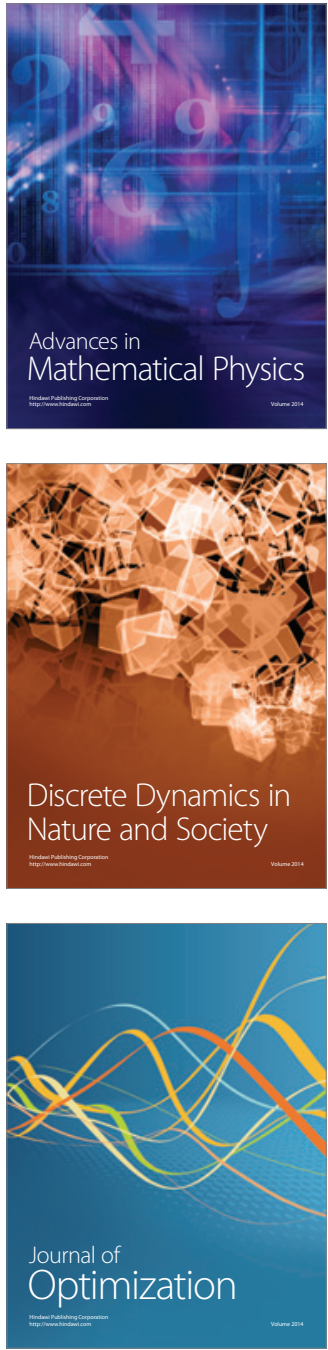